\title{
The study of appropriateness of Moderate income gap under the open perspective
}

\author{
Li Man \\ Zhejiang University of Water Resources and Electric Power \\ Hangzhou,Zhejiang,310018 China
}

\begin{abstract}
This article focuses on what is appropriateness of moderate income gap, evaluation methods, evaluation index, measurement models and corrective measures, on the basis, the income gap between future residents pointed out that research should define a unified definition of moderate income gap, to further improve the income gap moderation evaluation system, and promote the development and diversification of the income gap comparative study modest measure methods, and strengthening the countermeasure study of income gap adjustment moderation.
\end{abstract}

Keywords- The income gap, moderation, measu rement model, the degree of coordination

\section{INTRODUCTION}

In a market economy, economic development must be accompanied by a certain degree of income disparity, and therefore, the income gap modest research has important practical significance, many scholars and institutions have designed some indicators to measure income inequality and evaluate whether it is reasonable. Since the reform and opening up, the income gap problem associated with moderate income gap continued to widen, this reality caused widespread concern academia, due to differences in income dis parity evaluation criteria and methods, scholars evaluation results are not the same, scholars' view on income gap evaluation are gap moderation theory, rich and poor divided theory, differentiation on a pole, polarization and gaps misconduct, to determine which income gap exists the current situation, it is necessary to ascertain the income gap moderate range, while the income gap is moderately related to the distribution of income under the current economic system, the effect of the policy, as well as future income distribution policy formulation adjust the route, so it is necessary to have a comprehensive review and summary of research results of modest income gap between residents.

\section{THE CONNOTATION OF APPROPRIATENESS OF INCOME} GAP CONNOT ATION

The research in adequacy of income inequality began in the 1990s. Beginning of the 21st century, a variety of its related concepts began to emerge, such as the State Planning
Institute of Macroeconomic Research Group raised its concept. Zhu Ping proposed coordination between rich and poor efficiency and fairness, defined moderation from both quantitative and qualitative aspects, which is the current mainstream view. For example, Ren Hongyan believes that the income gap moderation refers to a coordinated state at a certain time and historical conditions: the income gap in this state contribute to achieving efficient allocation of social resources, promoting sustained economic growth, but it also conducive to social stability and equity. Second, from a quantitative point of view determine whether income disparities moderate, and to distinguish moderation with reasonableness of the income gap. Overall, the majority of scholars believe that the definition of the income gap in moderation, not only should consider their coordination with economic growth, but also based on the measurement and analys is of rational component of income under the existing system ration income gap not only presented on quantity, but also the impact of income inequality on human perception and behavior, if the effectiveness of positive effects brought by the income gap is greater than or equal to the negative effects, we can say that the income gap is modest, But at the same time, due to the different emphasis of scholars on modest income gap, which is currently not yet formed a unified concept.

\section{THE FORMATION MECHANISM OF MODEST INCOME} GAP

About the formation mechanism of modest income gap, theory can be described as divergent viewpoints: education or human capital differences. Cai Fang and Du Yang said: difference in human capital is the main cause of the income gap. Luo ChuLiang and Li Shi's findings show that: the higher degree of education or human capital, the higher the income, the greater the income gap. Geographical location and natural resources policy institutional factors: Fan Gang and Wang Lu said: geographic location and other conditions of transport distance is an important cause of regional economic growth and income distribution. Yao Zhizhong and Zhousufang said that: the main source of income gap is the difference between the factor endowments. Liuwen xin and Ji Hang think: the impact of government policies: such as urbanization significantly narrowing the income gap between urban and rural areas, while expanding and opening up the financial expenditure which dragged big income gap. 
Marketization factor, development factor and reforms factors. Zhao Wei and $\mathrm{Li}$ Shi attributed income gap to factors affecting the development of reform and policy factors. Zhou Zhenhua said: According to Work and Distribution According to market-oriented efforts to enhance the widening difference between incomes levels Distance. Differences are in economic structure and productivity. Wan Kwong Wah said: change in economic structure is an important reas on for the widening income gap. Wang Xiaolu and Fan Gang said: between the eastern coastal and inland areas of the Midwest, in terms of both the absolute level of economic development, the gap is still expanding, which is mainly due to differences in productivity and capital flow. Looking at the modest nature of the income gap formation mechanism! Surviving or unresolved issues in the income gap have moderate resistance to the formation mechanism of using several causes most comprehensive and objective enough to be interpreted, the lack of systematic research, adopt qualitative analysis on the formation mechanism of moderate income gap, the lack of quantitative basis, such as the various influencing factors and their rate of contribution.

\section{MODERATEINCOMEGAP BETWEEN RESIDENTSOF THE EVALUATION}

\section{A. Income Gap adequacyevaluation criteria}

Currently, from two perspectives, scholars designed the evaluation criteria of modest income gap: First, from the perspective of objective evidence, looking whether income gap is compatible with economic growth as evaluation criteria. For example, Kuznets and Lewis evaluate the income gap from the perspective of adaptation and economic growth. Kenneth Lee and Zhang Ying identified the evaluation criteria of moderate income gap as capable of generating productive efforts and economic growth incentives. Second, from the perspective of subjective value judgments evaluate the income gap moderation. However, due to the formation of the income gap is the result of a variety of subjective and objective factors working together, so that simply evaluated from the perspective of a moderate income gap exists some shortcomings; therefore, some scholars try to adopt an objective empirical and subjective norms to evaluate the adequacy of the income gap.

\section{B. Income Gap adequacy evaluation index}

Indexes measure of income inequality is the basis of the size or extent of the income gap between resident's moderation evaluation study to whether the dimensionless standard measure of income inequality indicators divided into absolute and relative indicators, due to the more comprehensive measure of income inequality should have anonymity, homogeneity, and overall independence, metastatic and strong Loren

Hereby consistency characteristics, scholars tend to use the relative indicators to measure the degree of income inequality $\$$ relative indicators are widely used including the Gini coefficient, Theil index, coefficient of variation, poor index, Kuznets index, Atkins on Ahluwalia index and index, due to the presence of a single indicator in itself a great defect, which scholars try to adopt a comprehensive indicators to measure the size of the income gap. On this basis, according to scholars of moderate income gap evaluation principles, build a modest income gap index system.

\section{RELATED POLICY RECOMMENDATIONS}

\section{A. Adhere to focus on efficiency, maintain the principle of fairness}

Survey results show that the income gap among Chinese residents is very large, and the Gini coefficient has exceeded the warning level; for the relationship between fairness and efficiency, the majority of residents want to handle the relationship between efficiency and fairness of the initial distribution and redistribution, and redistribution should focus more on fairness. At the same time of big cake good cake

In the big cake at the same time points good cake, good points are shown in the higher education level, the higher the per capita income of households; education level and income gap is U-shaped relationship: the higher education level is, the stronger income gap widening tolerance is, and also the higher the satisfaction of the income distribution is. This suggests that education as an important source of human capital plays an increasingly important role in promoting economic development, so better showing the increase in knowledge yields among income distribution system reform. Due to the duality of the labor market, the situation is decided that the traditional labor market is in a state of oversupply due to the less technical content, and the labor force of low educational level are employed mainly in the traditional labor market, resulting in lower income level because of fierce competition in the market of labor. However in the modern labor market, which require a higher level of technology labor force, the labor force of higher education level is almost employed in this market, resulting in a short supply or roughly balanced state, so the higher the income level of the workforce is. Strengthening equal opportunities for education, increasing investment in public education funding, further increasing investment in human capital, especially the investment in human capital among low-income communities, and providing equitable educational opportunities for each worker, are important measures to narrow residents income gap. Therefore, the Government should expand expenditure on education, and especially increase the investment in underdeveloped areas, poor areas, minority areas so that these residents enjoy equal access to education, improve the quality of workers and skills through education, increase the knowledge content of labor and creativity, so that workers and increase revenue. In order to adapt to accelerate the transformation of economic development, economic restructuring needs, in particular strengthening vocational education, skills training and continuing education, and improving the quality of workers and skills is helpful to the labor market liquidity factor to overcome structural unemployment, and increase the income of workers, thus narrowing the income gap. 


\section{B. Consummating tax system, strengthening tax administration, regulating excessively high incomes}

The questionnaire survey results showed that on the focus of equitable distribution promotion policy, more than half of the respondents chose to improve the tax system, give full play to the role of tax regulation, which also shows an important role taxation play in the income gap. In China, there is considerable room for improvement of the distribution of tax redistribution process. However, China's tax such problems as the imperfect system of personal income tax levy classification and collection and, besides that personal income tax, consumption tax and property tax system are not perfect, the inheritance tax, gift tax and social security taxes are not levied, in addition to personal income tax collection and administration to implement the classification system is not sound, poor oversight and other issues, so that the distribution of income tax adjustment function weak body. Therefore, to give full play to the role of the tax adjustment income gap, we need to establish a sound tax system and administration system, including having a role in regulating income distribution gap. According to the changes of the residents income, price impact, basic living expenses, etc. personal tax should be made reasonable adjustment. We should strengthen tax collection and administration, crack down on stealing, escape and evasion behavior, especially the monopoly industries, high-income people management and monitoring of taxable income, effectively regulate excessively high incomes. At the same time we can combine with national conditions, gradually begin to collect the inheritance tax, gift tax, social security tax, property tax, special consumption tax and other taxes, and regulate excessively high incomes.

\section{Forming reasonable wage determination mechanisms and salary growth mechanisms}

For the key of policy to promote equitable distribution, more than half of the respondents choose to create salary growth mechanism, which further shows the significance of the establishment of wage growth mechanism for improving the citizens' income. In the initial distribution of income, the implementation of collective wage negotiation system, improving disadvantaged workers in the initial distribution of narrowing the income gap b plays an important role. China's ordinary workers especially migrant workers employed in the SME personnel mobility, low level of organization in a weak position in wage bargaining. As businesses wage distribution system reform is not in place, business owners and the unequal status of workers, capital is obviously in a strong position in the enterprise distribution, resulting in imbalance of income distribution, and causing the widening income gap. In a market economy, enterprise should have control of distribution of income, but the company decisions are not unilaterally decided by the operators, but by both parties through equal consultation. Therefore, the focus of the Chinese enterprises to deepen reform of the income distribution system and the direction should be in accordance with the overall salary collective consultation system. The so-called collective wage negotiations, is an enterprise trade union or employee representatives, in accordance with law and business representatives on an equal footing within the enterprise wage distribution system, the wage distribution in the form of wage income level and other matters, signed a wage agreement on the basis of consensus in behavior. Collective consultation on wages is helpful to increase the collective wage negotiations workers say, and change the situation wages unilaterally decided by the company. Establishing collective wage negotiation system, is to improve the socialist market economy, corporate income distribution system to deal with the relationship between efficiency and fairness, regulate distribution order to ensure that the outcome of the reform and development of the workers, an important way to promote the construction of harmonious society. To improve collective wage consultation system, we need to establish a sound strong trade union (Confederation), establish a sound system of trade union work and operational mechanisms for collective bargaining under way over generations. To improve collective wage consultation system, we need to negotiate the subject of equality, consultation content specialization; consultative process standardization, supervision and consultation of other aspects of the system forced a breakthrough to achieve a balanced wage distribution, sharing and efficiency.

\section{ACKNOWLEDGMENT}

This paper is funded by moderate resident income disparities research under the open perspective in Zhejiang Province which is from professional development project for visiting scholar teachers colleges in Zhejiang Province in 2013.

\section{REFERENCES}

[1] Wang LiJuan, Zhou Bo. Questionnaire Chinese Sport Management System two decades [J]. SPORT S SCIENCE,2002,06:4 -6.

[2] State Planning Institute research group income gap between urban residents in China macroeconomic analysis moderation. [J]. Macroeconomic Research,2002,06:52-57.

[3] Xiaolin Peng. Chinese Sports Management System Reform Research Review. [J]. XI'AN INST ITUTE OF PHYSICAL, 2005,01:23-26.

[4] Liu Dongfeng. Path of Chinese Sports Management System Reform. [J]. Chengdu Institute of Physical Education, 2005,02:20-23

[5] Sun Keyi, Qin Chun Lin. Discussion Sports Management System and Chinese Sport Management System [J]. Beijing Sport University, 1995,01:6-13.

[6] Song JiXin. On the Reform and Development of China's sports management system structure [J]. Sports science,1998,01:16-19.

[7] Han Bing .Strategic choice for Olympic Games Chinese sports system reform after 2008. SPORTS ADULT,2006,02:33-34.

[8] Peng Teng. Modest income gap analysis [J]. ECONOMICS College (Social Science Edition),2006,03:32-34. 